\title{
Microscale Evaluation of Tight Oil Mobility: Insights from Pore Network Simulation
}

\author{
Yongchao Wang ${ }^{1,2,3,4, *}$, Yanqing Xia ${ }^{1}$, Zihui Feng ${ }^{3,4}$, Hongmei Shao ${ }^{3,4}$, Junli Qiu ${ }^{1}$, Suping Ma ${ }^{1}$, \\ Jiaqiang Zhang ${ }^{1,2}$, Haoyuan Jiang ${ }^{1,2}$, Jiyong $\mathrm{Li}^{1,2}$, Bo Gao ${ }^{3,4}$ and Lingling $\mathrm{Li}^{3,4}$ \\ 1 Northwest Institute of Eco-Environment and Resources, Chinese Academy of Sciences, \\ Lanzhou 730000, China; yqxia@lzb.ac.cn (Y.X.); qiukangjun@163.com (J.Q.); supingma@163.com (S.M.); \\ zhangjiaqiang18@mails.ucas.ac.cn (J.Z.); jianghaoyuan@nieer.ac.cn (H.J.); Lijiy09@163.com (J.L.) \\ 2 University of Chinese Academy of Sciences, Beijing 100049, China \\ 3 Research Institute of Petroleum Exploration and Development, Daqing Oilfield of CNPC, Daqing 163000, China; \\ fengzihui@petrochina.com.cn (Z.F.); shhm@petrochina.com.cn (H.S.); gb915@petrochina.com.cn (B.G.); \\ lilingling1984@petrochina.com.cn (L.L.) \\ 4 Heilongjiang Provincial Key Laboratory of Shale Oil \& Tight Oil Accumulation, Daqing 163712, China \\ * Correspondence: wangyongchao19@mails.ucas.ac.cn
}

check for updates

Citation: Wang, Y.; Xia, Y.; Feng, Z.; Shao, H.; Qiu, J.; Ma, S.; Zhang, J.; Jiang, H.; Li, J.; Gao, B.; et al. Microscale Evaluation of Tight Oil Mobility: Insights from Pore Network Simulation. Energies 2021, 14, 4580. https://doi.org/10.3390/en14154580

Academic Editors: Jianchao Cai, Reza Rezaee, Victor Calo and Jalel Azaiez

Received: 18 June 2021 Accepted: 22 July 2021 Published: 28 July 2021

Publisher's Note: MDPI stays neutral with regard to jurisdictional claims in published maps and institutional affiliations.

Copyright: (c) 2021 by the authors. Licensee MDPI, Basel, Switzerland. This article is an open access article distributed under the terms and conditions of the Creative Commons Attribution (CC BY) license (https:// creativecommons.org/licenses/by/ $4.0 /)$.

\begin{abstract}
Pore network modeling based on digital rock is employed to evaluate the mobility of shale oil in Qingshankou Formation, Songliao Basin, China. Computerized tomography technology is adopted in this work to reconstruct the digital rock of shale core. The pore network model is generated based on the computerized tomography data. We simulate the dynamics of fluid flow in a pore network model to evaluate the mobility of fluid in shale formation. The results show that the relative permeability of oil phase increases slowly in the initial stage of the displacement process, which is mainly caused by the poor continuity of the oil phase. In the later stages, with the increase in the oil phase continuity, the range of relative permeability increases. With the increase of organic matter content, the permeability of the water phase remains unchanged at low water saturation, but gradually increases at high water saturation. At the same time, it can be seen that, with the increase in organic matter content, the isosmotic point of the oil-water phase permeability shifts to the left, indicating that the wettability to water phase gradually weakens.
\end{abstract}

Keywords: shale oil; mobility; pore network model; relative permeability

\section{Introduction}

Shale oil is a new hotspot of unconventional resources exploration and development, after shale gas. Shale oil has achieved great success in North America [1], forming the second peak growth of crude oil production in the United States, which has greatly alleviated the energy pressure of the US and made the energy independence of the US a reality [2]. The successful commercial development of the US shale oil has profoundly affected international energy and reshaped the global energy industry $[3,4]$. China is rich in shale oil resources, such as Cretaceous in Songliao Basin, Permian in Junggar Basin, Triassic in Ordos Basin, Paleogene, Neogene in Bohai Bay Basin and Jianghan Basin, etc. [5,6].

As one of the top ten continental super basins in the world, Songliao Basin contains rich hydrocarbon resources [7]. Conventional hydrocarbon resources in the north of Songliao Basin have supported the efficient exploration and development of the Daqing oilfield for more than 60 years, which has made great contributions to Chinese energy security and Chinese economic development [8]. However, after decades of exploration and development in the Daqing oilfield, the remaining resources are hard to develop, as the residual reserves are of poor quality and the recovery rate is low $[9,10]$. Therefore, new areas of reserve resources are urgently needed to ensure the revitalization and development of Daqing Oilfield. There are abundant shale oil resources in the Qingshankou formation in northern Songliao Basin. The evaluation of shale oil mobility has become the focus of shale 
oil exploration and development [11]. Researchers usually adopt relative permeability to estimate the percolate ability of a formation [12].

Relative permeability measurement by physical experiment mainly includes two methods: unsteady-state method and the steady-state method [13]. The steady-state method is when a constant flow or pressure is applied at the injection end to determine permeability. The physical core-permeability test method is an effective method for conventional reservoirs [14]. However, the measurement of gas permeability requires multiple pressure points for testing. Due to the gas slippage effect (Klingberg effect) [15,16], the test's accuracy needs higher experimental pressure for tight cores, which makes the test process of the steady-state method for measuring permeability complicated [17]. The permeability is obtained through a trend line, which limits its accuracy. To overcome the problems above, the unsteady-state method is mainly used to measure gas permeability [18]. This method is based on the direct correlation between the gas leakage rate and the core permeability. However, the pore structure and mineral composition of shale is complex, so the phase permeability curve cannot be measured by the conventional steady-seepage method or unsteady-seepage method [19]. Therefore, the numerical simulation method to test the permeability of shale formation becomes a viable alternative method [20].

Pore network modeling (PNM) is a micro, multiphase flow -method based on physical reality [21]. In the field of hydrocarbon resources development, various forms of pore network models have been widely used in the simulation and prediction of single or multiphase flow parameters in porous rock media, such as capillary force [22], relative permeability [23], residual oil saturation [24], reservoir recovery [25], etc. PNM is also a simulation tool based on the actual physical existence of multiphase flow in porous media [26]. It can complete the simulation of flow in the media with a low computational cost and thereby obtain the relevant attribute parameters, such as relative permeability, capillary force and oil saturation [27]. The advantage of pore network modeling is that it enables flow simulation at the pore scale that is not considered by conventional basin-modeling methods [28]. The geometric model is the static part of the pore network model [29]. By extracting information from the real core image or generating it randomly by an algorithm, the pore and throat elements in porous media are simplified into geometrical shapes such as spherical, cylindrical or triangular prisms, which are easy to calculate and approximate to represent the complex porous media [30]. Pore network simulation is implemented by assigning attributes to the geometric model and embedding appropriate oil-water displacement mechanisms to simulate the process of oil-water flow in porous media.

In this work we will reconstruct the real shale digital rock by computed tomography (CT), and simulate the oil-water flow by pore network model. To the best of our knowledge, this is the first work that evaluates the shale oil mobility by real pore network modelling of the Qingshankou formation, Songliao Basin.

The paper structure is organized as follows. In Section 2, a real core is scanned by CT and the digital core is reconstructed, and the pore network model is generated. In Section 3, we simulate the dynamics of fluid flow in pore network models. The results are shown in Section 4, and main conclusions are given in Section 5.

\section{Reconstruction of Pore Network Model}

A PNM can be generated by two methods; the regular model, generated by an algorithm, and the irregular model, extracted by the information from the micron CT image respectively.

A regular model is a model whose size $\left(N_{\mathrm{x}} \times N_{\mathrm{y}} \times N_{\mathrm{z}}\right)$ is set before model generation. $N_{\mathrm{x}}, N_{\mathrm{y}}$, and $N_{\mathrm{z}}$ are the number of nodes in the directions of $x, y$ and $z$ axes. The regular model is a kind of relatively idealized model, generated artificially. Although the number of nodes in the model is determined in the regular model, the size of the element representing the pore throat in the model can be generated according to the distribution of the porethroat radius of the target core. Researchers can select appropriate pore-throat distribution schemes based on research purposes. Two commonly used pore-throat distribution schemes 
include the uniform pore-throat distribution scheme [31] and the truncated normal porethroat distribution scheme [32]. The uniform pore throat distribution scheme can be used to analyze the influence of some factors on the hydrocarbon migration and accumulation process, under the condition of a uniform pore-throat distribution, in the model. Truncated normal pore-throat distribution schemes can be used to analyze the influence of some factors on the migration and accumulation process of hydrocarbon under different porethroat distribution schemes. In both schemes, the distribution of pore-throat radii is mainly controlled by parameters such as the maximum pore-throat radius $R_{\max }$, the minimum pore-throat radius $\mathrm{R}_{\min }$ and the normalized parameter $\mathrm{N}$. The mathematical description of these two methods can be given by the following equations.

The equation for a uniform pore-throat distribution scheme:

$$
f(r)=\left\{\begin{aligned}
\frac{1}{R_{\max }-R_{\min }}, & R_{\min } \leq r \leq R_{\max } \\
0, & \text { otherwise }
\end{aligned}\right.
$$

The equation for a truncated normal pore-throat distribution scheme:

$$
f(r)=\left\{\begin{array}{cl}
\mathrm{N}\left(\mathrm{R}_{\max }-r\right)\left(r-\mathrm{R}_{\min }\right), & \mathrm{R}_{\min } \leq r \leq \mathrm{R}_{\max } \\
0, & \text { otherwise }
\end{array}\right.
$$

The regular model cannot reflect the characters of the shale core. In this work, we will reconstruct the pore network with real digital rock by means of nano-CT scanning, and a $3 \mathrm{D}$ grayscale image of real core pore-throat space will be obtained. The nano-CT resolution is $50 \mathrm{~nm}$. The voxel size of the image is $25 \mathrm{~nm} \times 25 \mathrm{~nm} \times 25 \mathrm{~nm}$. Figure 1 shows the cross section obtained by nano-CT scanning. The left image shows the raw data; it is unclear and needs image processing. In this work we will process the raw data by the nonlocal means filter method. As a new denoising technology proposed in recent years, nonlocal means filtering makes full use of the redundant information in the image and preserves the detailed features of the image to the greatest extent while denoising. The estimated value of the current pixel is obtained by the weighted average of pixels in the image that have a similar neighborhood structure to it.

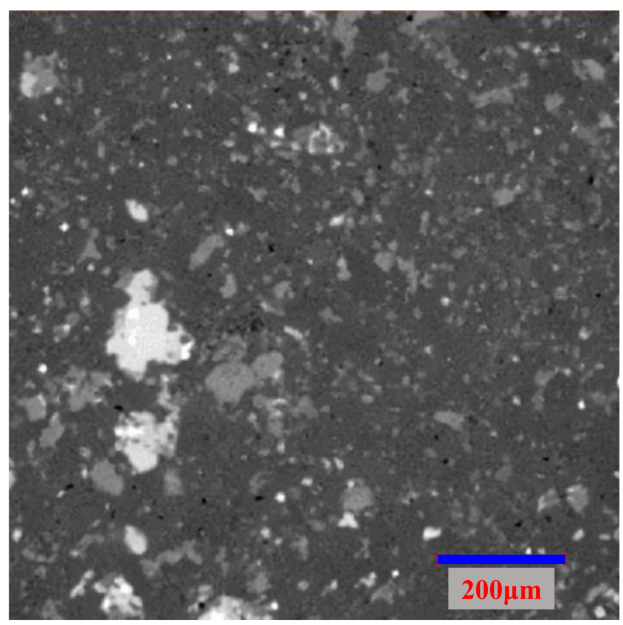

(a)

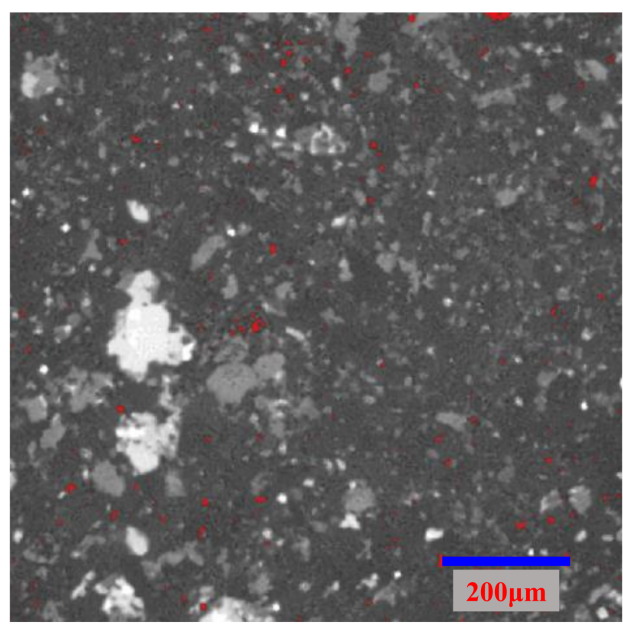

(b)

Figure 1. Segmentation of image. (a) is the original image. (b) shows the segmentation process, and the red dots represent the location of pores.

After image processing, we gained clear images, and the pores were recognizable in the processed raw images. A watershed algorithm was adopted to recognize the pores in the digital rock. The watershed transform is a kind of imitation map morphology-segmentation algorithm of an immersion process and its essence is the use of regional characteristics of image-to-image segmentation; it combines the advantages of edge detection and region 
growing to be able to afford a wide, single-pixel, connected, closed position that is a truly accurate contour, therefore this kind of image segmentation method is widely used. Figure $1 \mathrm{~b}$ shows the segmentation process, and the red dots represent the location of pores.

After image processing and segmentation, the pores are extracted from the digital rock. Figure 2 shows the extracted pores. In Figure 2a, the grey represents the matrix of rock, and the red represents the pores; in Figure $2 b$, the pores are extracted separately, and the red represents the pores of the digital rock.

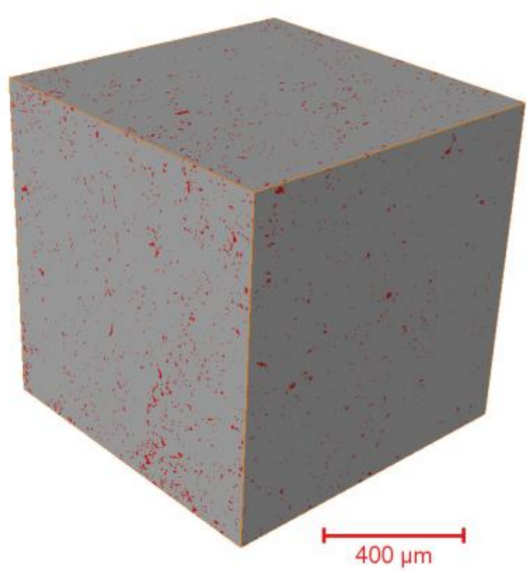

(a)

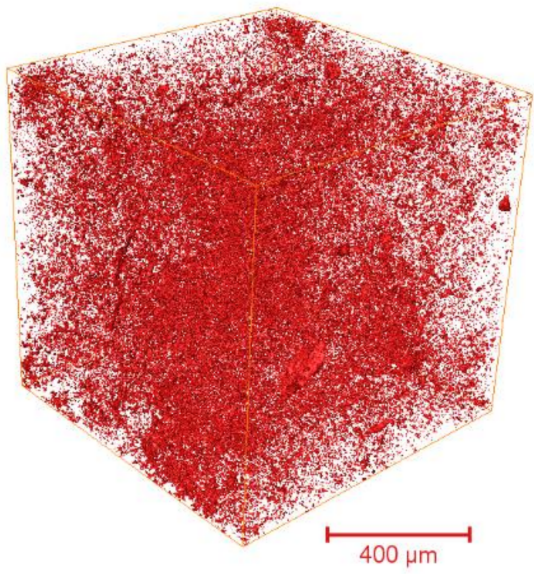

(b)

Figure 2. Segmentation of image. (a) The original image; the grey represents the matrix of rock, and the red represents the pores. (b) The segmentation process; the red dots represent the location of pores.

As shown in Figure 3a, with the extracted pores of the digital rock, a pore network model can be generated using the maximum ball [33] method. Figure $3 \mathrm{~b}$ shows pore and throat size distribution. The seed fill algorithm [34] is adopted to recover the connectivity of the digital rock.

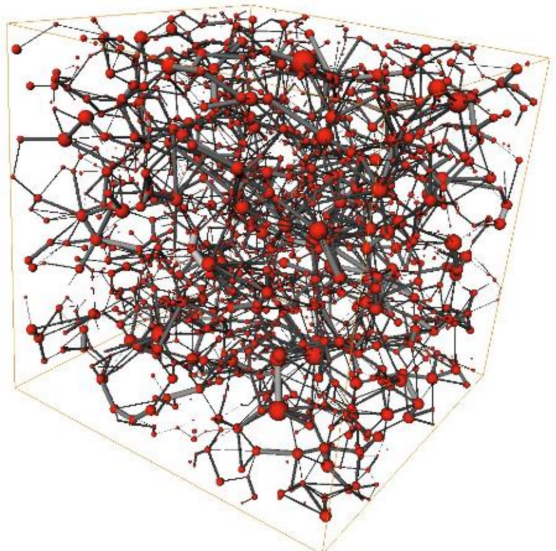

(a)

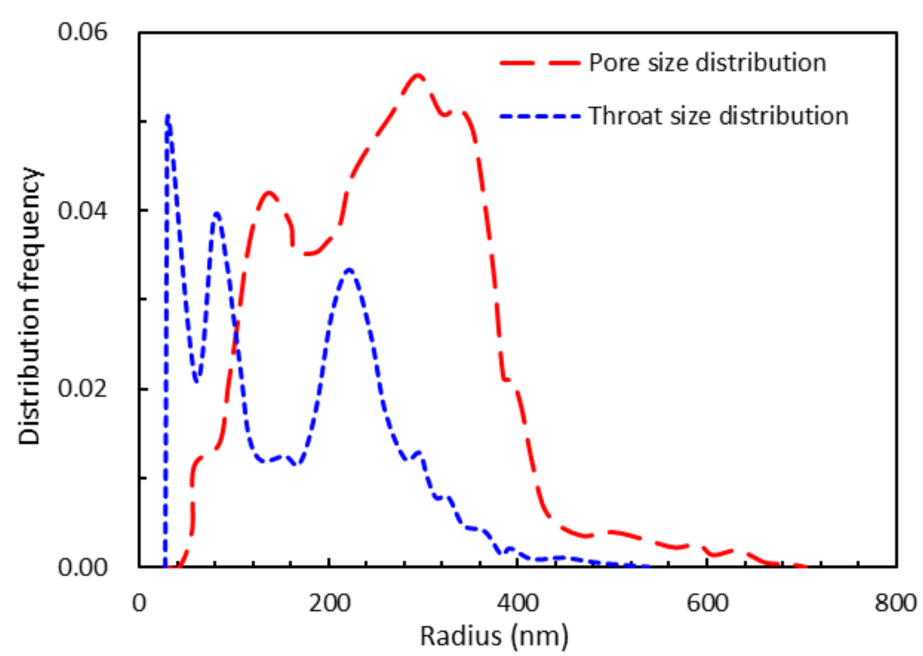

(b)

Figure 3. (a) A pore network model of digital rock. The gray represents the throats, the thickness of the cylinder represents the size of the throat, the red represents pores, and the diameter of the spheres indicates the size of the pore. (b) Pore and throat size distribution. 


\section{Pore Network Model Simulation}

Multiphase flow in porous media is mainly affected by viscous force and capillary force. The relationship between capillary force and viscous force in two-phase displacement can be measured by capillary number. It can be formulated in various ways, one of which is $N_{\mathrm{c}}=v \mu / \sigma$, where $v$ is displacement velocity; $\mu$ is viscosity; and $\sigma$ is the interfacial tension between the displacing and displaced phases [6]. In general, when the capillary number is high, the viscous force is dominant and the fluid flow velocity is fast. When the capillary force is low, the capillary pressure plays a dominant role and the fluid velocity is slow. Tight reservoirs have a large proportion of nanoscale pores, which are characterized by low porosity and low permeability. Therefore, many scholars $[6,15,19]$ believe that the capillary force is more important than the viscous force in the process of oil migration and accumulation. This means that the migration and accumulation of shale oil is more inclined to the steady-state migration mode, dominated by capillary force.

The pore network models are mainly divided into two types: quasi-steady state models and dynamic state models. The quasi-steady state model ignores the viscous force in the flow process, and the displacement process and the fluid distribution in each pore are controlled by capillary force. The saturation in each pore will not change, under the condition that the magnitude of capillary force remains unchanged, but only changes under the condition that the capillary force in the pore changes. Compared with the dynamic model, its calculation process is simpler and the amount of calculation is smaller. The dynamic model is suitable for the study of two-phase fluid systems, where both capillary and viscous forces are important factors. It can simulate the fluid injection process with constant pressure or constant flow rate. The dynamic model is realized by solving the pressure field of the entire pore network, and then gradually updating the fluid parameters and phase states in the model. Some studies $[34,35]$ found that when the capillary number is less than $10^{-6}$, the quasi-steady state model is sufficient to characterize multiphase flow in porous media. Obviously, the migration and accumulation process of shale oil satisfies this condition. Under the premise of accuracy and for convenience, we use the quasi-steady state pore network model to solve and analyze the migration and accumulation of shale oil. It should be noted that a flow mechanism in organic reservoirs is not involved in most existing pore network models. In order to accurately simulate the migration and accumulation process of shale oil, it is necessary to separate the flow laws in organic and inorganic pores.

The pore network is used to simulate the primary oil flooding process. It is assumed that, initially, inorganic pores are completely saturated with water and organic pores, which are oil-wet, are filled with an oil phase. In the primary drainage process, the pressure of the wetting phase (water) is constant, while that of the non-wetting phase (oil) is gradually increased. The conditions under which the oil phase will enter inorganic pores is determined by the local capillary pressure in the pore. On this occasion, the capillary pressure exhibits resistance factors. When capillary pressure reaches the capillary entry pressure of the pore, the non-wetting phase will enter the inorganic pore and occupy the center of the pore, with the displaced phase remaining on the solid surface. The volume of the residual wetting phase depends on the thickness of the wetting film. Water film thickness is not easy to measure experimentally, so we use the disjoining pressure theory to calculate the water film thickness [15]. In the following part, we mainly elaborate on the flow characteristics in organic pores and inorganic pores.

\subsection{Water Phase Flow Characteristics}

In inorganic shale pores, water mainly exists in two forms: capillary water and water film attached to the solid wall. For capillary water, the flow rate can be expressed as:

$$
q_{i n-w}=\frac{\pi r^{4}}{8 \mu_{w}} \frac{d p}{d l}
$$


where in indicates inorganic pores, $\mathrm{w}$ indicates water phase, $q_{\text {in-w }}$ is water flow rate in inorganic pores, $\mu_{\mathrm{w}}$ is water viscosity, $r=D / 2$ and $D$ is pore diameter, $d p$ is the pressure difference and $d l$ is the length difference.

Conductance is defined as the volume flow rate per unit pressure gradient, so the conductance of capillary water is:

$$
g_{i n-w}=\frac{\pi r^{4}}{8 \mu_{w}}
$$

where $g_{i n-w}$ is the conductance of capillary water in inorganic pores.

Another form of water in inorganic substances is water film. According to continuum theory, the flow rate of water film can be expressed as [15]:

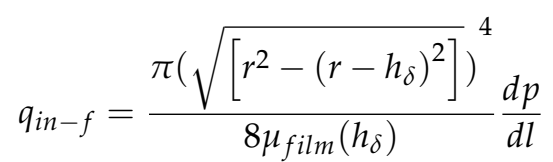

where $q_{i n-\mathrm{f}}$ is the flow rate of water film in inorganic pores, $h_{\delta}$ is the thickness of the water film, $\mu_{\text {film }}\left(h_{\delta}\right)$ is the viscosity of water film attached to solid wall and can be calculated by the method proposed by $\mathrm{Wu}$ [36].

Accordingly, the conductance of water film in inorganic pores can be formulated as:

$$
g_{i n-f}=\frac{\pi\left({\sqrt{\left[r^{2}-\left(r-h_{\delta}\right)^{2}\right]}}^{4}\right.}{8 \mu_{f i l m}\left(h_{\delta}\right)}
$$

where $g_{\text {in }-f}$ is the conductance of water film attach to solid wall.

In shale oil reservoirs, the size of most organic pores is nanometer scale, much smaller than that of inorganic pores. At the same time, the shale oil reservoirs are self-generated and self-stored. Therefore, in the migration stage of the oil phase, we assumed that the organic pores contain just the oil phases and do not contain capillary water or film water [15].

\subsection{Oil Phase Flow Characteristics}

The oil phase in inorganic pores mainly coexists with water film in the form of oil core, and the conductance of oil core is defined as:

$$
g_{i n-o}=\frac{\pi\left(r-h_{\delta}\right)^{4}}{8 \mu_{o}}
$$

where $g_{\text {in-o }}$ is the conductance of oil phase in inorganic pores, $\mu_{\mathrm{o}}$ is oil viscosity.

The wall surface of organic pores is usually hydrophobic, and in the migration process they are completely filled with the oil phase, which is generated by organic material. Therefore, similarly the flow rate of the oil phase in organic pores can be expressed as:

$$
g_{o r-o}=\frac{\pi r^{4}}{8 \mu_{0}}
$$

where or indicates organic pores, $g_{\text {or-o }}$ is the conductance of oil phase in organic pores.

\section{Results and Discussion}

\subsection{Evaluation of Reservoir Flow Characteristics}

Based on the pore network model established above, we evaluated the flow characteristics of the digital cores extracted from the Qingshankou formation, which mainly include absolute permeability and relative permeability.

The pressure and temperature are set as $0.1 \mathrm{MPa}$ and $300 \mathrm{~K}$ in the simulation, respectively. The simulated absolute permeability of shale oil core is $1.3 \times 10^{-3} \mathrm{mD}$, and the porosity is $8 \%$, which agrees with the previous experimental results of shale oil reservoir [37]. When simulating the migration process of shale oil in the target block, we set the upper limit of capillary pressure to $50 \mathrm{MPa}$ to allow a full drainage process, and further 
simulated the oil-water two-phase permeability curve in the drainage process, as shown in Figure 4. It can be seen from the figure that the critical oil saturation was 0.163 . That means when the oil phase saturation is higher than 0.163 , the oil phase forms a continuous phase through the pore network and begins to flow. It should be noted that at the connate water saturation, the oil phase relative permeability is close to 0.9 (less than 1 ); that is because the connate water, including capillary water and film water, hinders the flow of the oil phase due to the reduction in flow space and the interaction between two phases. The relative permeability of oil phase increases slowly in the initial stage of the displacement process, which is mainly caused by the poor continuity of oil phase through the pore network. In the later stage, with the increase of oil phase continuity and its occupation of center space, the relative permeability of oil phase increases rapidly. At the same time, we can see that the shale oil reservoir is mainly composed of nanopores, and the connate water saturation is high, which reaches 0.3 . However, the permeability of water phase is extremely low when water saturation is less than 0.4 . The two-phase co-seepage area is only 0.457. Low co-seepage area means less recoverable oil from the reservoir.

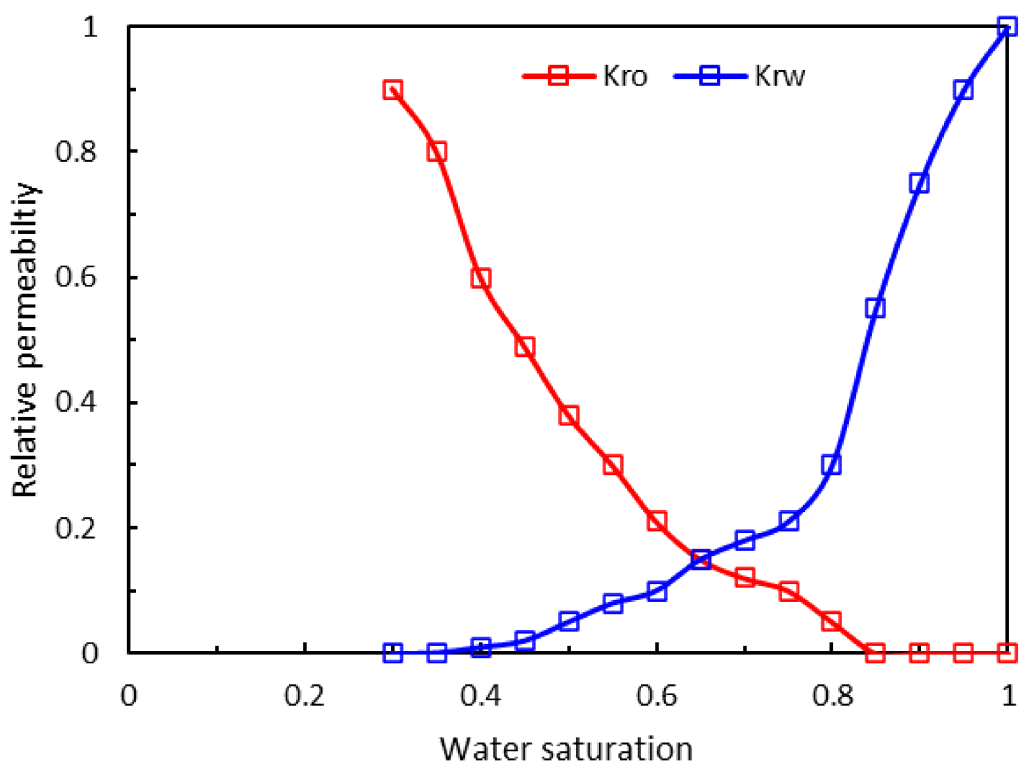

Figure 4. Relative permeability curves during drainage process.

\subsection{Effects of Organic Matter on Flow Characteristics}

The development degree of organic matter in shale is an important index for evaluating the development potential of shale reservoirs, and it is also an important factor affecting the two-phase seepage in shale porous media. Therefore, we investigated the influence of organic matter on the absolute permeability and relative permeability during the oil migration process of a shale oil reservoir by changing the organic matter content of pore network while keeping the pore structure unchanged. We assumed that the organic pores were randomly distributed in the network, and were extracted from our sample by changing the wettability of pore elements.

We set the pore volume fraction of organic pores at $0 \%, 10 \%, 20 \%$ and $30 \%$. On this basis, the absolute permeability and oil-water two-phase relative permeability curves of a series of pore networks with different organic matter contents were simulated with pressure at $0.1 \mathrm{MPa}$ and temperature at $300 \mathrm{~K}$. The measured single-phase permeability of porous media varied with different fluids [38]. It was also affected by interactions between solid surface and fluid, such as wettability [39]. Here, we used water phase absolute permeability to describe the flow capability of porous media. The relationship between absolute permeability and organic matter content, in our case, is shown in Figure 5. It can be seen that, with the increase in organic matter content, the absolute permeability of the water phase increases. This is because of the strong hydrophobicity in organic pores; 
the seepage speed of the water phase in organic pores is higher than that in inorganic pores. The presence of organic matter pores can improve the seepage capacity of the aqueous phase; when the content of organic matter pores increased from $0 \%$ to $30 \%$, the absolute permeability of the aqueous phase increased from $0.8 \times 10^{-3} \mathrm{mD}$ to $3.79 \times 10^{-3}$ $\mathrm{mD}$. The relationship between relative permeability and organic matter content during drainage process, in our case, is shown in Figure 6. The simulation results showed that, with the increase in organic matter content, the relative permeabilities of the water phase are identical at low water saturation, but gradually increase at high water saturation. This is because, at high water saturation, the continuity of the water phase is enhanced, and the enhanceming effect of organic matter on water phase seepage is more obvious. At the same time, it can be seen that with the increase of organic matter content, the isosmotic point of oil-water two-phase relative permeability shifts to the left, indicating that the wettability of the water phase gradually weakens, which is reasonable due to the increased proportion of organic matter.

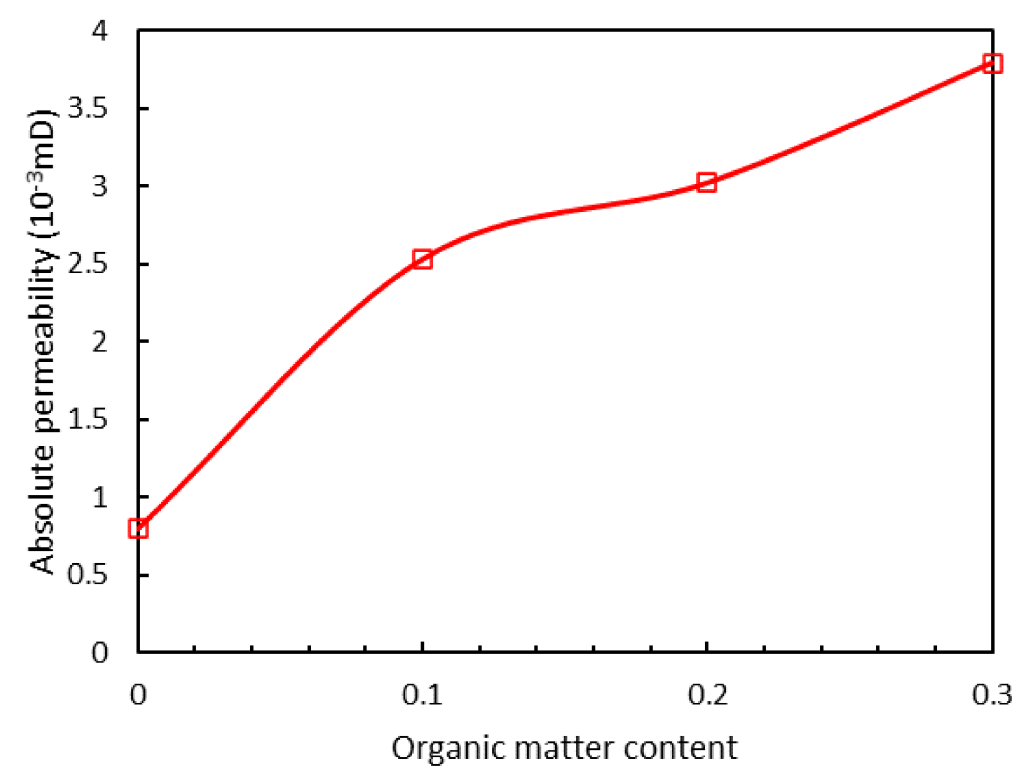

Figure 5. The relationship between absolute permeability and organic matter content.

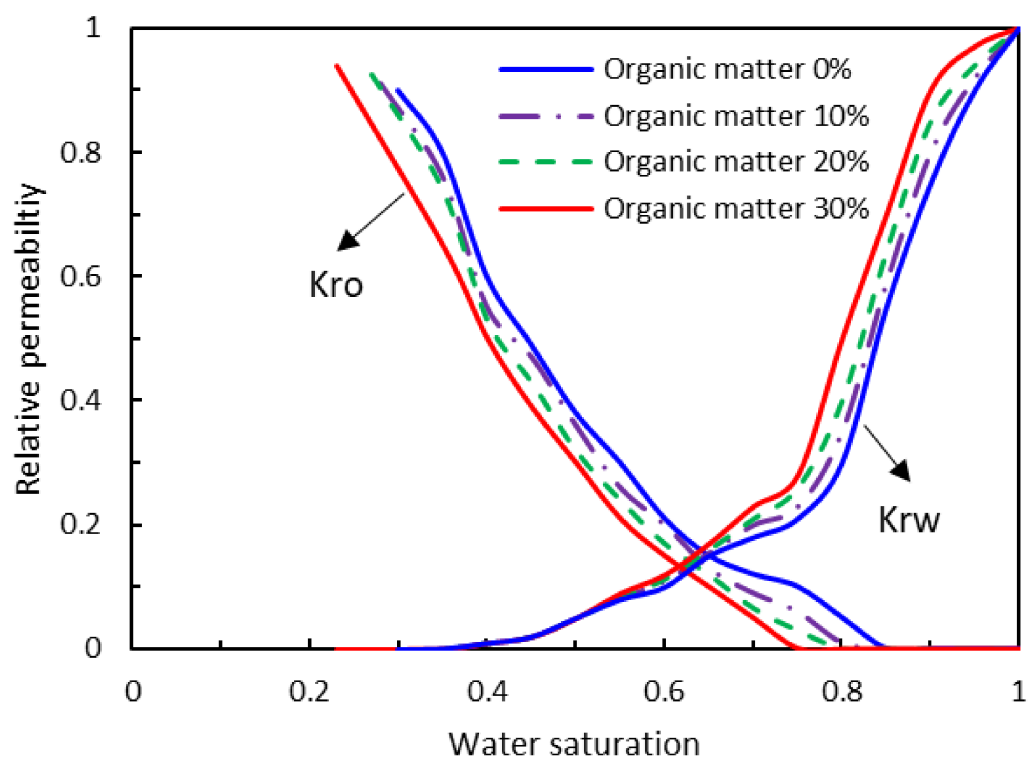

Figure 6. The relationship between relative permeability and organic matter content during migration process. 


\section{Summary and Conclusions}

In this work, we analyzed the pore characteristics of the Qingshankou formation shale by scanning electron microscope. Computerized tomography technology was adopted in this work to reconstruct the rock of the shale core digitally. A pore network model was generated, based on the computerized tomography data, and the hydrocarbon migration process was simulated by PNM. The main conclusions are summarized as follows:

1. The shale oil reservoir is mainly nanopore, and the bound water saturation is high, reaching 0.3. However, the permeability of the water phase is extremely low when water saturation is less than 0.4 . The two-phase co-seepage area is only 0.457 . Low co-seepage area means less recoverable oil from the reservoir.

2. With the increase in organic matter content, the relative permeabilities of water phase are identical at low water saturation, but gradually increase at high water saturation. This is because, at high water saturation, the continuity of the water phase is enhanced, and the promoting effect of organic matter on water phase seepage is more obvious.

3. With the increase in organic matter content, the isosmotic point of oil-water phase permeability shifts to the left, indicating that the wettability of the water phase gradually weakens.

Author Contributions: Methodology, J.Q.; software, S.M., H.J., J.L., B.G. and L.L.; data curation, J.Z., Z.F., H.S.; writing—original draft preparation, Y.W. and J.Z.; writing—review and editing, Y.X.; supervision, Y.X.; funding acquisition, Y.X. All authors have read and agreed to the published version of the manuscript.

Funding: This research received no external funding.

Institutional Review Board Statement: Not applicable.

Informed Consent Statement: Not applicable.

Data Availability Statement: All relevant data have been presented in this paper.

Conflicts of Interest: The authors declare no conflict of interest.

\section{References}

1. Wu, Z.; He, S.; Han, Y.; Zhai, G.; He, X.; Zhou, Z. Effect of Organic Matter Type and Maturity on Organic Matter Pore Formation of Transitional Facies Shales: A Case Study on Upper Permian Longtan and Dalong Shales in Middle Yangtze Region, China. J. Earth Sci. 2019, 31, 368-384. [CrossRef]

2. Maugeri, L. The Shale Oil Boom: A US Phenomenon; Harvard Kennedy School Belfer Center for Science and International Affairs, Harvard Kennedy School: Cambridge, MA, USA, 2013; Discussion Paper 2013-05.

3. Zanganeh, B.; Ahmadi, M.; Hanks, C.; Awoleke, O. The role of hydraulic fracture geometry and conductivity profile, unpropped zone conductivity and fracturing fluid flowback on production performance of shale oil wells. J. Unconv. Oil Gas Resour. 2015, 9, 103-113. [CrossRef]

4. Feng, Q.; Xu, S.; Xing, X.; Zhang, W.; Wang, S. Advances and challenges in shale oil development: A critical review. Adv. Geo-Energy Res. 2020, 4, 406-418. [CrossRef]

5. Kong, X.; Zhang, C.; Liu, D.; Jiang, S.; Luo, Q.; Zeng, J.; Liu, L.; Luo, L.; Shao, H.; Liu, D.; et al. Disequilibrium partial melting of metasediments in subduction zones: Evidence from O-Nd-Hf isotopes and trace elements in S-type granites of the Chinese Altai. Lithosphere 2018, 11, 149-168. [CrossRef]

6. Zhao, W.; Jia, C.; Jiang, L.; Zhang, T.; He, M.; Zhang, F.; Jiang, Z.; Li, X.; Wu, K. Fluid charging and hydrocarbon accumulation Rio de Janeiro in the sweet spot, Ordos Basin, China. J. Pet. Sci. Eng. 2021, 200, 108391. [CrossRef]

7. Pei, F.; Xu, W.; Yang, D.; Zhao, Q.; Liu, X.; Hu, Z. Zircon U-Pb geochronology of basement metamorphic rocks in the Songliao Basin. Chin. Sci. Bull. 2007, 52, 942-948. [CrossRef]

8. Li, Q.; Kang, C.; Wang, H.; Liu, C.; Zhang, C. Application of microbial enhanced oil recovery technique to Daqing Oilfield. Biochem. Eng. J. 2002, 11, 197-199. [CrossRef]

9. Zhao, W.; Zhang, T.; Jia, C.; Li, X.; Wu, K.; He, M. Numerical simulation on natural gas migration and accumulation in sweet spots of tight reservoir. J. Nat. Gas Sci. Eng. 2020, 81, 103454. [CrossRef]

10. Han, G.; Liu, Y.; Nawnit, K.; Zhou, Y. Discussion on seepage governing equations for low permeability reservoirs with a threshold pressure gradient. Adv. Geo-Energy Res. 2018, 2, 245-259. [CrossRef]

11. Zhao, W.; Jia, C.; Zhang, T.; Jiang, L.; Li, X.; Jiang, Z.; Zhang, F. Effects of nanopore geometry on confined water flow: A view of lattice Boltzmann simulation. Chem. Eng. Sci. 2021, 230, 116183. [CrossRef] 
12. Liu, L.; Zhang, Z.; Li, C.; Ning, F.; Liu, C.; Wu, N.; Cai, J. Hydrate growth in quartzitic sands and implication of pore fractal characteristics to hydraulic, mechanical, and electrical properties of hydrate-bearing sediments. J. Nat. Gas Sci. Eng. 2020, 75, 103109. [CrossRef]

13. Honarpour, M.; Mahmood, S. Relative-Permeability Measurements: An Overview. J. Pet. Technol. 1988, 40, 963-966. [CrossRef]

14. Cai, J.; Hu, X.; Xiao, B.; Zhou, Y.; Wei, W. Recent developments on fractal-based approaches to nanofluids and nanoparticle aggregation. Int. J. Heat Mass Transf. 2017, 105, 623-637. [CrossRef]

15. He, M.; Zhou, Y.; Wu, K.; Hu, Y.; Feng, D.; Zhang, T.; Liu, Q.; Li, X. Pore network modeling of thin water film and its influence on relative permeability curves in tight formations. Fuel 2021, 289, 119828. [CrossRef]

16. Cai, J.; Hajibeygi, H.; Yao, J.; Hassanizadeh, S.M. Advances in porous media science and engineering from InterPore2020 perspective. Adv. Geo-Energy Res. 2020, 4, 352-355. [CrossRef]

17. Berg, S.; Unsal, E.; Dijk, H. Non-uniqueness and uncertainty quantification of relative permeability measurements by inverse modelling. Comput. Geotech. 2021, 132, 103964. [CrossRef]

18. Singh, H.; Mahabadi, N.; Myshakin, E.M.; Seol, Y. A Mechanistic Model for Relative Permeability of Gas and Water Flow in Hydrate-Bearing Porous Media With Capillarity. Water Resour. Res. 2019, 55, 3414-3432. [CrossRef]

19. He, M.; Zhou, Y.; Chen, B.; Zhang, T.; Wu, K.; Feng, D.; Li, X. Effect of Pore Structure on Slippage Effect in Unsaturated Tight Formation Using Pore Network Model. Energy Fuels 2021, 35, 5789-5800. [CrossRef]

20. Gostick, J.T.; Ioannidis, M.; Fowler, M.W.; Pritzker, M.D. Pore network modeling of fibrous gas diffusion layers for polymer electrolyte membrane fuel cells. J. Power Sources 2007, 173, 277-290. [CrossRef]

21. Maalal, O.; Prat, M.; Lasseux, D. Pore network model of drying with Kelvin effect. Phys. Fluids 2021, 33, 027103. [CrossRef]

22. Raeini, A.Q.; Yang, J.; Bondino, I.; Bultreys, T.; Blunt, M.J.; Bijeljic, B. Validating the Generalized Pore Network Model Using Micro-CT Images of Two-Phase Flow. Transp. Porous Media 2019, 130, 405-424. [CrossRef]

23. Xie, C.; Raeini, A.Q.; Wang, Y.; Blunt, M.J.; Wang, M. An improved pore-network model including viscous coupling effects using direct simulation by the lattice Boltzmann method. Adv. Water Resour. 2017, 100, 26-34. [CrossRef]

24. Wood, D.A.; Hazra, B. Characterization of organic-rich shales for petroleum exploration \& exploitation: A review-Part 1: Bulk properties, multi-scale geometry and gas adsorption. J. Earth Sci. 2017, 28, 739-757. [CrossRef]

25. Aljasmi, A.; Sahimi, M. Fast simulation of two-phase flow in three-dimensional digital images of heterogeneous porous media using multiresolution curvelet transformation. Adv. Water Resour. 2021, 150, 103882. [CrossRef]

26. Viswanathan, H.S.; Hyman, J.D.; Karra, S.; O’Malley, D.; Srinivasan, S.; Hagberg, A. Advancing Graph-Based Algorithms for Predicting Flow and Transport in Fractured Rock. Water Resour. Res. 2018, 54, 6085-6099. [CrossRef]

27. Kohanpur, A.H.; Valocchi, A.J. Pore-Network Stitching Method: A Pore-to-Core Upscaling Approach for Multiphase Flow. Transp. Porous Media 2020, 135, 659-685. [CrossRef]

28. Bo, D.; Jiang, L.; Zhao, W.; Jiang, Y.; Liu, H.; Ou, H. Geochemical Characteristics and Oil Source Correlation of Minfeng Area, Dongying Depression, China. Geofluids 2021, 2021, 1-11. [CrossRef]

29. Cesare, B.; Parisatto, M.; Mancini, L.; Peruzzo, L.; Franceschi, M.; Tacchetto, T.; Reddy, S.; Spiess, R.; Nestola, F.; Marone, F. Mineral inclusions are not immutable: Evidence of post-entrapment thermally-induced shape change of quartz in garnet. Earth Planet. Sci. Lett. 2021, 555, 116708. [CrossRef]

30. Wardlaw, N.C.; Li, Y.; Forbes, D. Pore-throat size correlation from capillary pressure curves. Transp. Porous Media 1987, 2, 597-614. [CrossRef]

31. Ferreira, F.C.; Booth, R.; Oliveira, R.; Boyd, A.; Bize-Forest, N.; Wahanik, H. Truncated Multi-Gaussian Pore-Throat-Size Decomposition and a New Universal J-Function for Rock Characterization of Complex Carbonate Reservoirs; OTC Brasil: Rio de Janeiro, Brazil, 2015. [CrossRef]

32. Dong, H.; Blunt, M. Pore-network extraction from micro-computerized-tomography images. Phys. Rev. E 2009, 80, 036307. [CrossRef]

33. Dullien, F.A. Porous Media: Fluid Transport and Pore Structure; Academic Press: Cambridge, MA, USA, 2012.

34. Nguyen, V.H.; Sheppard, A.; Knackstedt, M.A.; Pinczewski, W.V. The effect of displacement rate on imbibition relative permeability and residual saturation. J. Pet. Sci. Eng. 2006, 52, 54-70. [CrossRef]

35. Wu, P.; Nikolov, A.; Wasan, D. Capillary dynamics driven by molecular self-layering. Adv. Colloid Interface Sci. 2017, 243, 114-120. [CrossRef]

36. Liu, J.; Sheng, J.J. Experimental investigation of surfactant enhanced spontaneous imbibition in Chinese shale oil reservoirs using NMR tests. J. Ind. Eng. Chem. 2019, 72, 414-422. [CrossRef]

37. Heckbert, P.S. A seed fill algorithm. Graph. Gems 1990, 275, 275-277. [CrossRef]

38. Wu, Y.; Pruess, K.; Persoff, P. Gas Flow in Porous Media with Klinkenberg Effects. Transp. Porous Media 1998, $32,117-137$. [CrossRef]

39. Huang, D.; Sendner, C.; Horinek, D.; Netz, R.R.; Bocquet, L. Water Slippage versus Contact Angle: A Quasiuniversal Relationship. Phys. Rev. Lett. 2008, 101, 226101. [CrossRef] [PubMed] 